\title{
Work in Progess: Methods Implemented by a Non-Traditional Textbook to Enable Student Success in Engineering
}

\section{Mr. David Reeping, Ohio Northern University}

David Reeping is a sophomore majoring in Engineering Education with a minor in Mathematics and an undergraduate research assistant. He is a Choose Ohio First scholar inducted during the 2012-2013 school year and the recipient of the Remsberg Creativity Award for 2013. Also, he is a member of the freshman honorary society (Alpha Lambda Delta / Phi Eta Sigma) and the mathematics honorary society (Kappa $\mathrm{Mu}$ Epsilon). His research interests involve improving mathematical perseverance and literacy in students and exploring general topics in K-12 engineering (student perceptions of engineering).

\section{Dr. Kenneth J. Reid, Ohio Northern University}

Ken Reid is the Director of Engineering Education, Director of First-Year Engineering and Professor in Electrical and Computer Engineering at Ohio Northern University. He was the seventh person in the U.S. to receive a Ph.D. in Engineering Education from Purdue University. He is active in engineering within K-12, serving on the TSA Boards of Directors and over 10 years on the IEEE-USA Precollege Education Committee. He was awarded with an IEEE-USA Professional Achievement Award in 2013 and named the Herbert F. Alter Chair of Engineering in 2010. His research interests include success in first-year engineering, introducing entrepreneurship into engineering, international service and engineering in $\mathrm{K}$ 12. 


\section{Work in Progress: Methods Implemented by a Non-Traditional Textbook to Enable Student Success in Engineering}

\section{Introduction}

Math pedagogy continues to be discussed and debated in the K-12 environment amidst introduction of Common Core and Next Generation Science Standards (NGSS). Instructors are now put in a potentially awkward position as they are required to integrate the foreign subject of engineering, the "e" in STEM education, with little to no background or context. While teachers can enhance their knowledge of new teaching strategies through attending STEM workshops at or outside of their school, current textbooks fail to include authentic engineering examples and thus offer little to no support to teachers. Also, few textbooks offer content that foster mathematical perseverance and literacy. Instead, these texts prefer to stampede on without clarification on algebraic or conceptual steps that may be ambiguous to students. With these points in mind, a math textbook which integrates engineering at a practical and understandable level would be immensely valuable as teachers strive to satisfy the new standards (both Common Core and NGSS) and prepare students to pursue engineering degree programs. This paper describes the development of this textbook.

To effectively communicate engineering and mathematics to students, the author of the text is an undergraduate student majoring in Engineering Education, mentored by a professor with the terminal degree in the field. The student formed an advisory board of teachers willing to participate in the development of this text through guiding questions and reviewing sample chapters. By following educator input and seeking consultation from the student's mentor and university mathematics department, a textbook or supplement founded in Engineering Education pedagogy should be a welcomed boost in the K-12 movement of integrating engineering, targeting student difficulties in mathematics, and promoting student success in STEM degree programs.

Methods utilized in the development of this textbook will be continually discussed with the advisory board (concept and results), use of language, and pedagogical foundation (teaching philosophy).

\section{Background}

An undergraduate student majoring in Engineering Education is in the process of writing a mathematics textbook which integrates engineering concepts for high school students. To ensure this project is properly managed, the student is being advised and assisted by a professor with a Ph.D. in Engineering Education to ensure proper engineering examples are included. An advisory board of volunteer teachers is serving as a resource for reviewing text samples, offering ideas, and answering questionnaires relevant to the text. The student is also seeking assistance or advice from the university mathematics and engineering departments when appropriate.

The student (author) has progressed in developing content for this text based on an initial discussion and additional research, including numerous reports on the state of student performance in college mathematics ${ }^{1,2}$. In its current state, the diction and approach is to focus 
on essential skills needed to succeed in a STEM degree and make engineering a more accessible subject in particular.

To supplement the content, extended problems involving the engineering design process, critical and creative thinking, and technology applications (such as JMP, Pspice, TI Calculator software, CAS) are planned for inclusion.

The textbook offers an authentic opportunity to tie content to the Next Generation Science Standards and Common Core standards in Mathematics. Authentic examples provide a realistic context in, for example, "Defining and Delimiting Engineering Problems" (NGSS) and "Model with mathematics," from the Standards of Mathematical Practice in the Common Core, Mathematics standards ${ }^{3,4}$.

\section{Reflection on Mathematics Textbooks Before Development}

Textbooks have been the common tools for communicating mathematics to students alongside the demonstration of practice problems on the board. Yet, even this most readily available conduit for enhancing a student's knowledge can go underutilized; this is especially true in the math classroom. The author can describe a topic with as much detail and finesse as he or she chooses; yet, this does not mean the student is invested in the material - this essentially eliminates the value of the textbook as a learning tool.

Despite efforts to read the textbook outside of class, students report difficulty not just in comprehension, but reading $5,6,7$. For the student who is weak in mathematics, reading a textbook is almost like learning a second language. Because reading a math textbook is distinctly different than reading other textbooks, students must develop the ability to read in the mathematical sense. The concept of "mathematical literacy" is emphasized by Kilpatrick; in fact, he advises that this skill is best begun early in K-8 ${ }^{8}$. Given students that are "mathematically illiterate," traditional textbook writing will fail in communicating necessary information to the readers.

One could infer that visual learning can take a prominent role, considering students have problems with reading a math textbook. If a text could deformalize mathematics and present it holistically, students may be more apt to comprehend the nature of math rather than all of the definitions and rules ${ }^{9}$. Perhaps the outcomes assigned to each class need to be reevaluated and what exactly is expected of each student upon completing the class must be determined ${ }^{8}$. Through this realization, the pedagogy of a math class can be better defined and, in turn, better communicated.

By their nature, textbooks hold all of the information to cover a certain subject within the scope of the intended grade level. Yet, it is ultimately up to the teacher how the text is utilized. Since words like "comprehend" and "understand" are sparse through the Common Core standards, it is a frightening thought that math education could slip all the way back down to the bottom of Bloom's Taxonomy ${ }^{4,11}$. Instead of relying on the teacher to provide an explanation, these textbooks should be able to communicate the message in a way students can understand rather than acting as a "formula dictionary." 
In terms of integrating engineering, math texts consistently fall short by only including "plug and chug" problems that only utilize a formula with little to no critical thinking involved. In an NSF funded study, the investigators analyzed several textbooks to find instances of problems with an engineering context. Of the surveyed Algebra and Geometry texts, problems were not identified as engineering problems ${ }^{12}$. With the problems unlabeled or mislabeled, it is likely that students will not make the connection. The literature suggests that mathematics textbooks have been picked apart to find various essential components such as engineering. The inclusion of math has already been addressed in science textbooks considering the high attrition rate in engineering programs, which is partially caused by poor math preparation ${ }^{13}$.

By observation, trivial examples in which engineering formulas or geometry problems are citied as authentic applications tend to be prefixed by "an engineer wants to..." While these "plug and chug" and abstract problems have a certain place in math texts, special attention needs to be paid to those involve problem solving. Despite the fact that "real world problems" can be considered a buzzword, using completed or in-progress real world projects as condensed Model Eliciting Activities (MEAs) could allow for authentic applications of mathematic knowledge in a multidisciplinary scenarios ${ }^{14}$.

With all aspects of the literature in mind, the author set three main goals for the text: communicate essential mathematics effectively, represent the engineering profession authentically with appropriate application problems, and provide support to the student to ensure successful learning experience.

\section{Finding a Foundation for a Textbook to Authentically Incorporate Engineering}

The desired content and structure of the book was informed by an advisory board of teachers through three guiding questions ${ }^{1}$. At the time of the initial survey, teachers representing 10 different schools across 2 states offered to assist in this effort. The first round of questions was developed by the investigators to create some idea for the target for this project in terms of content and market. The teachers were sent the following questions:

1) What do you envision being covered in this text?

2) What topics do your students seem to struggle with? Are there topics that aren't covered as much or as well as you'd like in your current text?

3) Would you consider your current text to be underutilized by your students?

The responses focused mainly on STEM activities, applications of trigonometry, applications in physics and chemistry, and extended problems. Concerns were voiced over covering too much material and trying to make a text that can be described as a "jack of all trades but master of none." Proposed subjects to be adopted into the text included Calculus, Trigonometry, Statistics, Chemistry, Physics, and Engineering. 


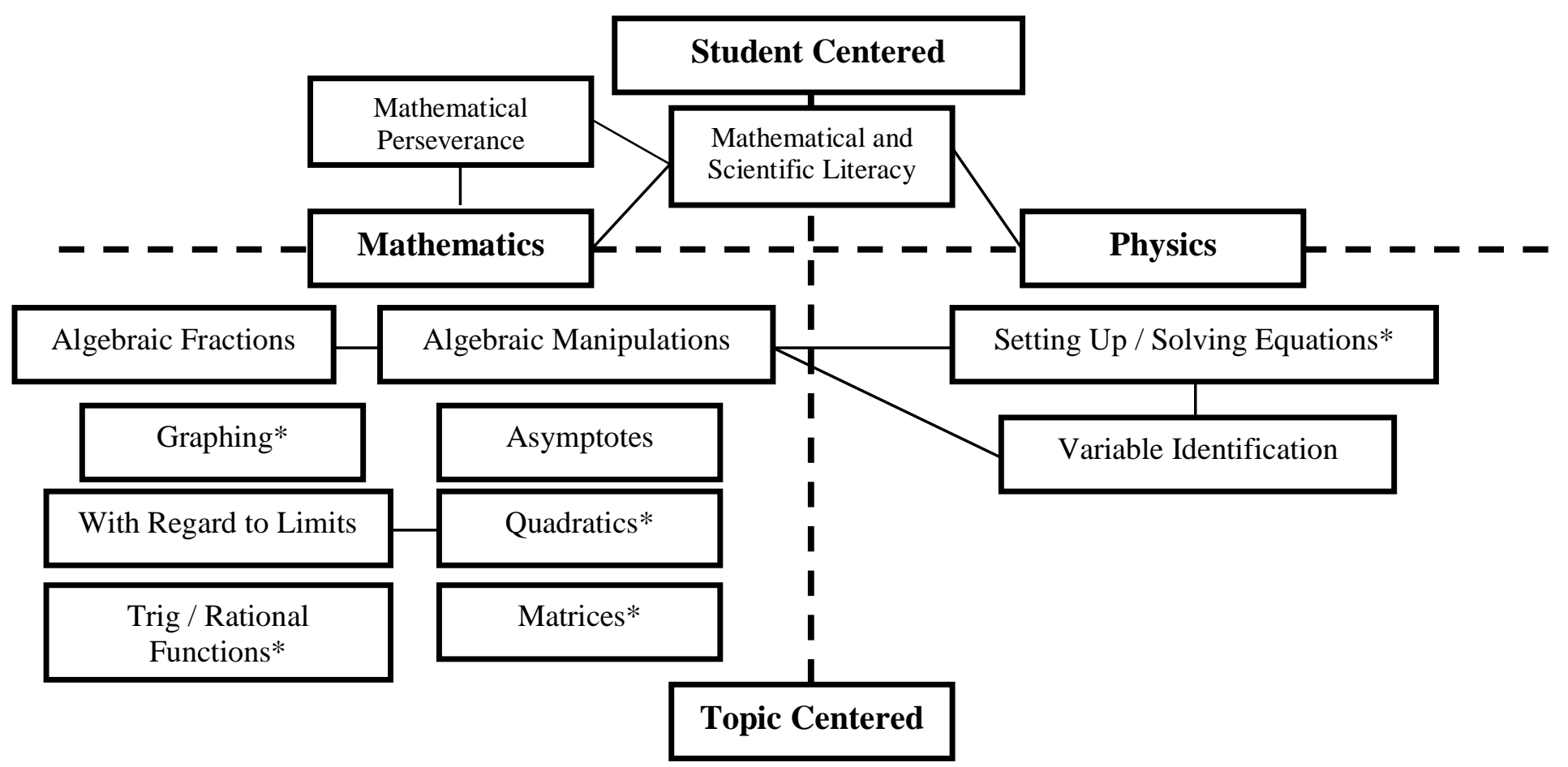

Figure 2: Observed Student Difficulties Reported by Advisory Board ${ }^{1}$

The second question focused on student difficulties. When comparing the web of student difficulties to the topics list in Figure 2, 5 of the 12 coincide at some capacity (marked with an asterisk). Ironically, the common topic of all three curricula, matrices, is an observed student difficulty in Figure 3. While this graphic does not present an exhaustive list of topics that need to be covered more in depth or better explained, it can serve as a guide for content development.

Figure 2 is divided into vertically into two categories: Mathematics and Physics. The area is further divided into four sectors vertically: Student Centered and Topic Centered Difficulties in Mathematics or Physics. Each sector contains an item that a teacher response highlighted as a difficulty among his or her students. Therefore, each entry in the area can be coded. For example, the item "Matrices" can be defined as a "Topic Centered Difficulty in Mathematics."

Some overlap occurred, specifically with "Variable Identification," "Setting Up / Solving Equations," and "Algebraic Manipulations." These concepts associated with simple algebra appeared often in the results. One Physics teacher explained, "It appears that if the equation has a bunch of x's, y's, and z's[,] students have little to no problem solving the equation for an unknown[;] [yet,] as soon as you put in velocity, acceleration, and time symbols, students make mistakes or outright act as though they have no idea how to solve it." It appears as though "variable identification" is a challenge for students to grasp, especially in the sciences.

In general, the advisory board focused exclusively on specific topics. However, mathematical perseverance was common among both math and physics teacher responses, surprisingly. One math teacher explained this idea, "Students need to develop mathematical perseverance; students are generally quick to give in when the answer either is not clearly apparent or the route to the answer is viewed as too lengthy." Another teacher reported, "Anything with multiple steps is an 
issue for my students... when there is a sign change...piece missing... or an extra piece...they just shut down." With this in mind, it is understandable that low student achievement can be directly traced to mathematical perseverance - especially with open ended problems. Literature exists that verifies the impact of low mathematical perseverance (confidence in doing mathematics) on students' academic achievement ${ }^{15,16,17}$.

\section{Content -- Comparing Curricula to Find the Textbook's Focus}

Figure 3 provides a glimpse into how much pre-engineering and early engineering curricula can differ. In the figure, there are three main categories, "Advanced Math for Engineering and Science," "Just in Time Math," and "First Year Engineering Courses." The web of concepts above is essentially a stripped down Venn diagram; under each category is list of topics exclusive to that curriculum. The bubbles that are with two or more other curricula are topics found in both.

"Just in Time Math" is a framework for a college course meant to prepare students who are struggling in an engineering program. On the other hand, "Advanced Math for Engineering and Science" is a curriculum for high school students to give them the necessary tools to succeed in a STEM degree program. Both "Just in Time Math" and "Advanced Math for Engineering and Science" have the same intention of preparing students for engineering coursework, at least for the first and second years ${ }^{18,19}$.

These curricula are compared to an "outcome tree" of a classification scheme to differentiate first year engineering courses. Each topic listed in the "outcome tree" is covered in an "Introduction to Engineering 1" or "Engineering 1" course at different universities - with the assumption that not every course is comparable ${ }^{20}$. Theoretically, each topic that could possibly be covered is listed. This comparison should in turn allow a student who completes the text to be better prepared to enter into a STEM degree program, particularly engineering. 


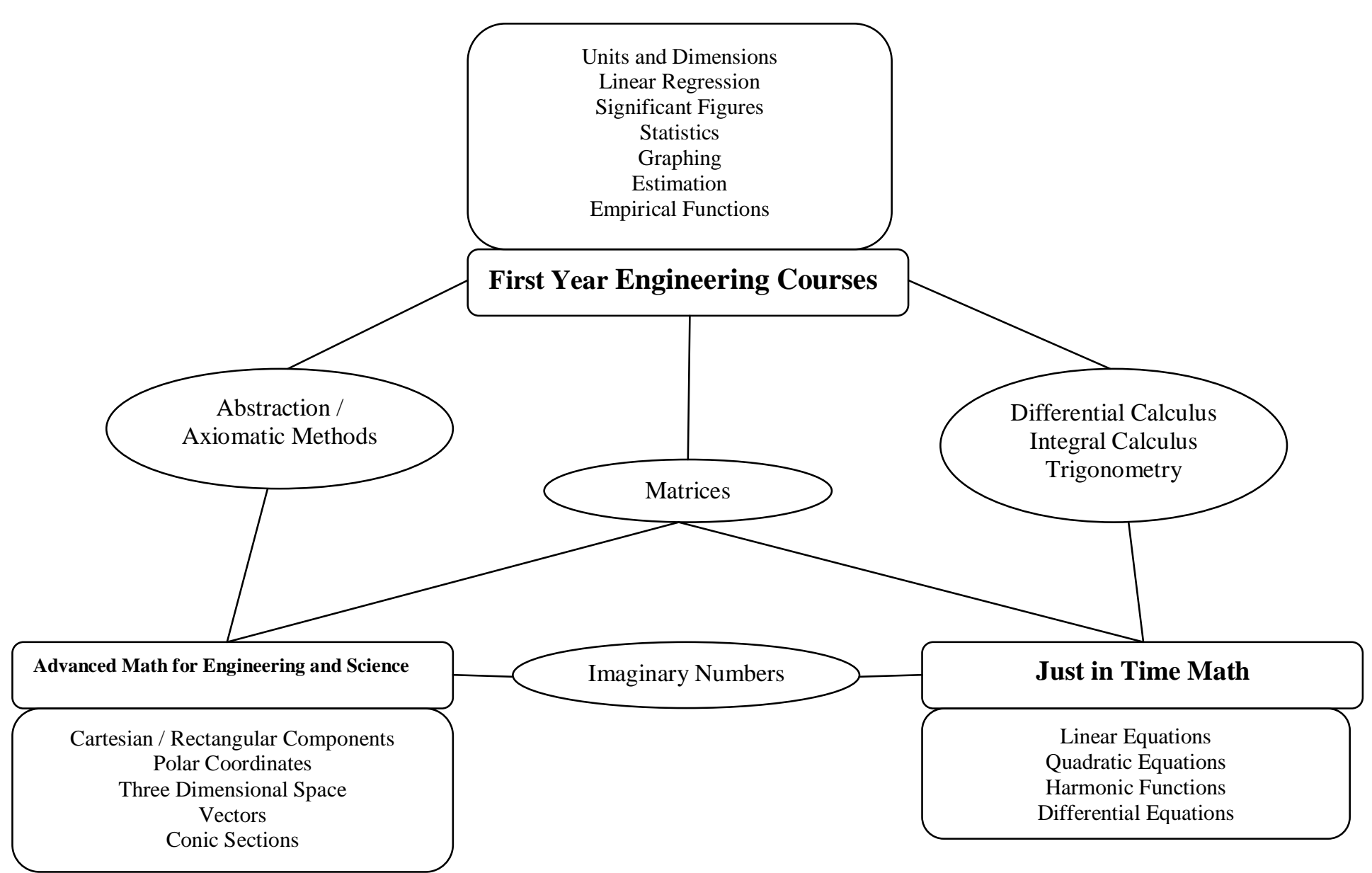

Figure 3: Comparing Two Sample Curriculums to Classification Scheme

When used as a "pseudo taste-test" to determine where supposed pre-engineering curricula fall, it is clear that some gaps exist. For example, the framework for "Advanced Math for Engineering and Science" was developed with consideration to Statics, Dynamics, Mechanics of Materials, and other studies on student achievement--particularly Aung, Underdown, and Quin ${ }^{18,21}$.

On the other hand, Just in Time Math acts as a comprehensive course to ensure students have seen just enough of the necessary math to succeed later in the curriculum. The layout of the course follows the format of the associated textbook, which is modeled off of a program developed at Wright State University ${ }^{19}$.

The classification scheme provides a glimpse of a first year engineering course by examining course outcomes. Using a checklist and a comprehensive list of outcomes collected through a Delphi study, users are able to determine their course's focus. This allows the user to meaningfully compare it to similar classes at other universities.

As an all encompassing representation of the mathematics found in engineering, the classification scheme fails to provide the necessary picture, considering it is not designed to 
encompass the whole year ${ }^{20}$. However, combined with teacher responses during a polling period to determine the content of the text, student difficulties revealed deficiencies in math skills at the most basic levels ${ }^{1}$. The Math Skills "Outcome Tree" is shown in Figure 4.

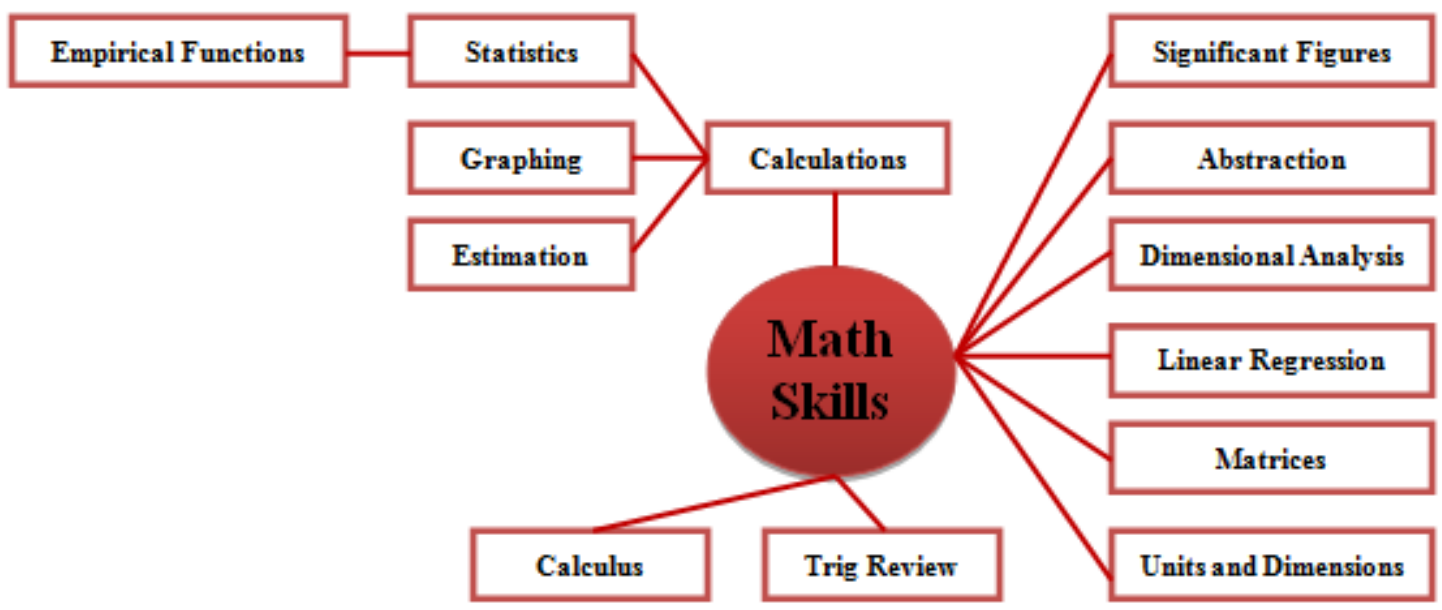

Figure 3: Outcome Tree for Math Skills from Classification Scheme 1,20

\section{Efforts to Target Student Difficulties and Integrate Engineering Concepts}

As mentioned, the "plug and chug" strand of problems is illustrated in Figure 5. The example of a DC circuit illustrates the incorporation of the idea of using equations to model actions or objects in real life, rather than mathematical equations introduced for their own sake. The student is given a situation where two voltage sources are connected to a node with three resistors branching out as shown in Figure 5.

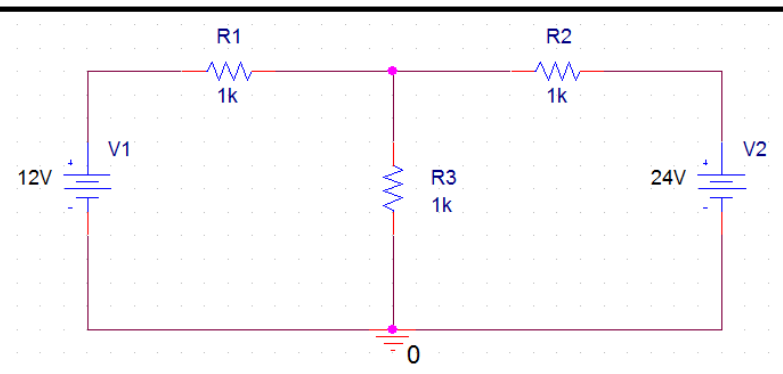

We're looking for the voltage drop, $V_{0}$, across $R_{3}$. Using nodal analysis, the following equation describes the circuit in terms of the voltage we want. Solve for $v_{0}$.

$$
\frac{v_{0}-12}{1000}+\frac{v_{0}-24}{1000}+\frac{v_{0}}{1000}=0
$$

Figure 5: Example Problem Involving Electric Circuits 
After an introduction to Nodal Analysis and Mesh Analysis to give the students an idea where the equations are coming from, the focus is shifted to competency in solving the resulting equation(s). Particularly with Nodal, the student needs to be comfortable in dealing with fractions and finding a common denominator. After simplifying, the remaining equation is linear.

$$
\frac{v_{0}-12}{1000}+\frac{v_{0}-24}{1000}+\frac{v_{0}}{1000}=v_{0}-12+v_{0}-24+v_{0}=0
$$

Solving for $v_{0}$, the result is $12 \mathrm{~V}$. This can be validated using PSPICE, which can serve as a good technology application if the class is able to access this program (Figure 6).

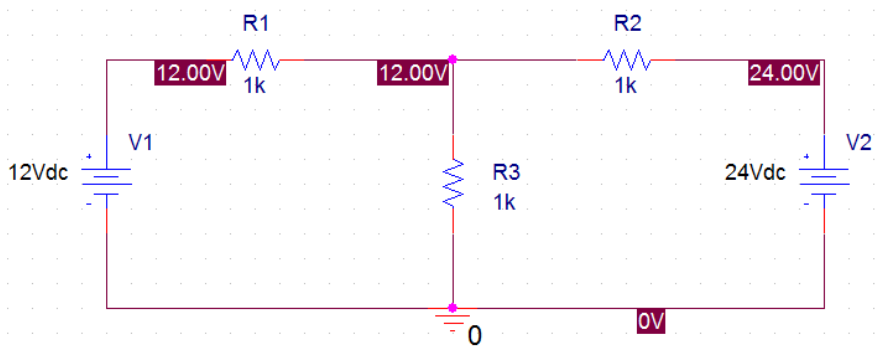

Figure 6: PSpice Solution

Even through the use of such a trivial example, the student needed to identify the variable (getting acclimated to using different variables instead of constantly seeing ' $x$ ' and ' $y$ '), simplify algebraic fractions, solve a linear equation, and verify using an electrical engineering program (when possible). More complex circuits challenge the student to solve increasingly difficult systems by utilizing matrices and implementing Cramer's Rule and / or Gaussian Elimination. Thinking further, electric circuits can provide an application for imaginary numbers in the context of $\mathrm{AC}^{1}$.

Statics provides another opportunity to include systems of equations through the equations of equilibrium with a tie to real life applications. Even a two dimensional case can have a set of three equations to serve as the algebraic representation of the situation. In fact, moments in three dimensions can include applications of vectors in the context of determinants and matrices.

$$
\left\{\begin{array}{l}
\sum F_{x}=0 \\
\sum F_{y}=0 \\
\sum M=0
\end{array}\right.
$$

These problems can scratch the surface of engineering applications, but they offer little in terms of critical thinking or problem solving. Instead, this strand of problems better suits the testing of student abilities in the context of an engineering problem. While these will be included to an extent, the later problems cater more to design thinking. 
Take the following proposed scenario for example:

A service group of engineers are approached to assist in the design of the water purification system in Haiti. A spring located 4 miles up a riverbed from a village has a waterline that flows into a 40,000 gallon reservoir. The reservoir supplies enough water pressure to reach 15 public fountains throughout a densely populated village. The water is captured at a significantly higher altitude, so the water must travel down an incline to feed into the public fountains though pipes of constant diameter. Upon the installation of this system, villagers would no longer need to hike up the mountainous terrain and carry water down one bucket at a time and purify the water using other unreliable methods.

This project is currently being addressed by an engineering service group at Ohio Northern University. In fact, many outreaches by this service group can become a centerpiece for discussion of engineering, science, and mathematics concepts in a realistic context. With an appropriate introduction to water purification, students can be asked to:

- Draw a model of the water purification system.

- Use Bernoulli's Principle in context.

- Consider two points: one at the collection point (A) and one at an arbitrary fountain (B). Bernoulli's principle relates the water pressure $(p)$, gravitational velocity $(g)$, velocity $(v)$, density $(\rho)$ and height above some reference height $(z)$. According to Bernoulli, these quantities will stay constant.

$$
\frac{1}{2} \rho v^{2}+\rho g z+p=\text { constant }
$$

This means that if a value changes on one side, there must be a change inversely on the other side. What is happening to the pressure and velocity from A to B?

- Use a process to effectively make decisions on design upon further briefing of the system (such as the cost and what constitutes "good" flow rate).

$\circ$ While the delivery system is functional, the water may contain debris by traveling down the piping system. Using your knowledge of the system, where should filters be placed? You may opt to use a decision matrix [covered elsewhere in the text] (consider Flow Rate, Cost, Availability, and Maintenance).

More problems related to this scenario and other engineering projects are in development. Testing among students is likely, but a certain amount of care needs to be taken when designing these problems. Teachers were sent a scenario that involved a simple circuit with two resistors, $R_{1}$ and $R_{2}$ (where one was a photo resistor), and a capacitor. Given the information, the problem involved determining the placement of $R_{1}$ and $R_{2}$ given the criteria.

Teacher responses can be summarized by one math teacher in particular who said the following: "As a math teacher I'm very intimidated by all of the electrical engineering notations in your sample problems. Although they sound impressive, I am overwhelmed at the thought of being able to implement them in my classroom when I'm not sure of the mathematics required for the problem." 
Another math teacher commented: " you may want to consider a section that explains what all of the units mean and how they relate to one another AND how to read the notation (ex: R sub 1, R sub 2, etc.) Many students become very intimidated when the seemingly harmless paragraph they are about to read turns out to be alphabet soup to understand."

It should be made clear that when designing projects for high school, appropriate foresight into not overcomplicating the subject and using such unfamiliar terminology that the students give up without even trying the problem. This practice is not just limited to textbooks, even Model Eliciting Activities can fall victim to this. Problems generated using real world projects as inspiration will be sent to the teachers with the initial discussion in consideration and modified. Appropriate edits will be made to ensure readability for students and allow teachers to effectively integrate the extended problems in the classroom.

\section{Conclusion}

While the text is certainly not complete, the framework surrounding has been defined and judged to be sound by a panel of K-12 teachers. The authors' intent is to avoid a textbook that becomes a library of formulas which covers far too much. This typical buffet approach will be cumbersome to students looking for an accurate depiction of "engineering math." The text will provide readers with a solid foundation of math skills without detracting from the roots of real word application, despite more abstract topics. Even those who do not enter into a STEM degree program will be exposed to mathematics necessary to complete the required credit hours for their specific major.

\section{References}

[1] Reeping, David, and Kenneth Reid. "An Engineering Education Initiative: Development of a STEM Mathematics Textbook." First Year Engineering Experience, 2013. Pittsburg, PA.

[2] Long, Mark C., Patrice Iatarola, and Dylan Conger. "Explaining gaps in readiness for college-level math: The role of high school courses." Education 4.1 (2009): 1-33.

[3] http://www.nextgenscience.org/hsets1-engineering-design Accessed: 9 Mar 2014.

[4] "Common Core Standards for Mathematics." Common Core State Standards Initiative.

[5] Weinberg, Aaron, and Emilie Wiesner. "Understanding mathematics textbooks through reader-oriented theory." Educational Studies in Mathematics 76.1 (2011): 49-63.

[6] Wang, J. An empirical assessment of textbook readability in secondary education. Reading Improvement, 33 (Spring '96), 41-45.

[7] Allington, Richard L. "You can't learn much from books you can't read." Educational Leadership 60.3 (2002): 16-19.

[8] Kilpatrick, Jeremy. "Understanding mathematical literacy: The contribution of research." Educational Studies in Mathematics 47.1 (2001): 101-116.

[9] Arcavi, Abraham. "The role of visual representations in the learning of mathematics." Educational Studies in Mathematics 52.3 (2003): 215-241.

[10] Duval, Raymond. "A cognitive analysis of problems of comprehension in a learning of mathematics." Educational studies in mathematics 61.1-2 (2006): 103-131.

[11] Andersen, Lorin W., and David R. Krathwohl. "A Taxonomy for Learning, Teaching, and Assessing: A Revision of Bloom's Taxonomy of Educational Objectives, Abridged Edition." (2001). 
[12] Quinn, Robert J., M. Sami Fadali, and Mike Robinson. "How do high school mathematics texts cover engineering and technology?" Frontiers in Education Conference, 2001. 31st Annual. Vol. 2. IEEE, 2001.

[13] Budny, D., Bjedov, G. and W. LeBold. 1997, November. Assessment of the impact of the freshman engineering Courses. Proc. 1997 Frontiers in Education Conf., Pittsburgh, PA.

[14] Diefes-Dux, Heidi A., et al. "A framework for posing open-ended engineering problems: Model-eliciting activities." Frontiers in Education, 2004. FIE 2004. 34th Annual. IEEE, 2004.

[15] Reyes, Laurie Hart. "Affective variables and mathematics education." The Elementary School Journal 84.5 (1984): 558-581.

[16] Kloosterman, Peter. "Self-confidence and motivation in mathematics." Journal of Educational Psychology 80.3 (1988): 345.

[17] McLeod, Douglas B. "Research on affect in mathematics education: A reconceptualization." Handbook of research on mathematics teaching and learning (1992): 575-596.

[18] Coriell, Joshua and Krystal Corbett. "An Innovative Approach to Secondary Mathematics for Engineering and Science," Proceedings of Frontiers in Education Conference, 2013, Oklahoma City, OK.

[19] Shadaram, Mehdi, Brandy Alger, and Mauli Agrawal. "Implementation of Just in Time and Revamped Engineering Math Courses to Improve Retention and Graduation Rates." Proceedings of Frontiers in Education Conference, 2013, Oklahoma City, OK

[20] Reid, Kenneth, David Reeping, Tyler Hertenstein, Graham Fennel, and Elizabeth Spingola. "Development of a Classification Scheme for "Introduction to Engineering" Courses" Proceedings of the Frontiers in Education Conference, 2013. Oklahoma City, OK.

[21] Aung, K, Underdown, R. Qian, Q. "K-12 Engineering Education Priorities, Research Themes, and Challenges," Proceedings of the American Society for Engineering Education Annual Conference, 2013, Atlanta, GA . 